\title{
Tables, Maps, and Figures
}

TABLES

o.1. GDP per capita, $1880-2000$

1.1. Chinese immigrant labor in mines and plantations in Indonesia and Malaysia, c. 1800

2.1. Conjectural demographic consequences of slave trading and raiding in the Indonesian archipelago, 1820-1850 (annual average)

2.2. Conjectural numbers for slave trading and raiding for Island Southeast Asia, 1820-1850

3.1. Geographical division of Java's population, 1815-1930 79

3.2. Hirschman index, 1913 and 1938

5.1. The capitals of the Netherlands Indies, British Malaya, and the Philippines in 1830 and 1930

MAPS

o.1. Island Southeast Asia

2.1. Slave-raiding routes, $1750-1880 \quad 48$

2.2. Slavery in early nineteenth-century Netherlands Indies 
3.1. Reconstruction of annual average net migration of indigenous Javanese population between Residencies, 1867-1894

3.2. Reconstruction of migration between Provinces in the northern Philippines, 1887-1903

FIGURES

1.1. Population growth in Island Southeast Asia, 1760-190o 